\title{
En Küçük Kareler Kollokasyon ve Kriging Yöntemleri ile Lokal Jeoid Belirleme
}

\author{
Yasemin ŞİSMAN ${ }^{1 *}$, Birol ELEVLİ ${ }^{2}$ \\ ${ }^{1}$ Ondokuz Mayıs Üniversitesi, Mühendislik Fakültesi, Harita Mühendisliği Bölümü, Samsun, Türkiye \\ ${ }^{2}$ Ondokuz Mayıs Üniversitesi, Mühendislik Fakültesi, Harita Mühendisliği Bölümü, Samsun, Türkiye
}

*Sorumlu Yazar: ysisman@omu.edu.tr

Geliş Tarihi: 25.07 .2018

Kabul Tarihi: 29.10 .2018

\section{$\ddot{O ̈ z}$}

Uydu jeodezisi teknikleri ile lokal jeoid belirleme çalışmaları ile son yıllarda artmıştır. Birçok arazi çalışmasında gerekli olan jeoid ondülasyonu $(\mathrm{N})$ ortometrik yükseklik $(\mathrm{H})$ ile ellipsoidal yükseklik (h) arasındaki fark ile hesaplanır. Jeoid belirlemek için Stokes formülü, Molodensky formülü, Hızlı furrier dönüşümü, Kaldır-hesapla-geriyükle, En küçük kareler Kollokasyon, ters mesafe, en yakın nokta, kriging enterpolasyon, polinomsal enterpolasyon, radyal temel fonksiyon, vb. Birçok yöntem vardır. En küçük kareler Kollokasyon yönteminde fonksiyonel model sinyal olarak adlandırılan hatayı içermektedir ve model ölçü hatalarının yanında sinyal hatasını da belirler. Kriging enterpolasyon yöntemi ise en yakın verileri kullanarak optimum değerleri hesaplama esasına göre çözüm yapar. Bu yaklaşımlar lokal jeoid belirleme çalışmalarında kullanılabilir. Bu uygulamada ilk olarak jeoid ondülasyonu değerleri hesaplanmıştır. Sonra, bu değerler kullanılarak En küçük kareler Kollokasyon ve Kriging interpolasyon yöntemlerine göre lokal jeoid yüzeyi belirlenmiştir. Uygulamanın sonunda, her iki yöntemden elde edilen karesel ortalama hatalr karşılaştırılmış ve yöntemlerin avantajları belirlenmiştir.

Anahtar Kelimeler: Lokal jeoid belirleme, ortometrik ve ellipsoidal yükseklik, en küçük kareler kollokasyon yöntemi, Kriging yöntemi.

\section{The Local Geoid Determination Using Least Square Collocation and Kriging Interpolation Methods}

\begin{abstract}
The local geoid determination applications increased last year depending on satellite technologies in geodesy. Geoid undulation $(\mathrm{N})$, obtained from ellipsoidal height $(\mathrm{h})$ to orthometric height $(\mathrm{H})$ is required for many geodetic and surveying applications. There are some methods for geoid determination like Stokes formulation, Molodensky formulae, Fast fourier transform (FFT) technique, Remove-compute-restore, Least squares collocation approach, Inverse distance, kriging, nearest neighbour, polynomial regression, radial basis function, etc. In least square collocation model, the errors of functional models known as signal can be easily determined. The Kriging interpolation predict the optimum value using the closest data. These approaches can be applied in local geoid determination. In the application firstly, the geoid undulation is calculated from ellipsoidal and orthometric heights. Then, the least square collocation and kriging interpolation methods are used to develop the local geoid surface. At the end of application the standard deviation of the methods were obtained and compared for determined advantages of methods.
\end{abstract}

Keywords: Local Geoid Determination, ellipsoidal and orthometric height, least square collocation methods, Kriging methods. 


\section{Giriş}

Yeryüzünün matematiksel şekli olarak 1872 yılında Listing tarafından tanımlan jeoid karmaşık bir yüzeydir ve matematiksel olarak kolayca tanımlanamaz. Bu tanımlamadan sonra bölgesel jeoid belirlenmesi jeodezinin önde gelen çalışma alanlarından birisi olmuştur (Aksoy ve Güneş, 1990). Jeoid belirleme, yatay konumu bilinen bir noktada jeoid yüksekliğinin sayısal veya analog olarak elde edilmesini sağlayacak biçimde verilerin modellenmesidir (Ayan ve Deniz, 2000). Konum belirleme yöntemlerinde uydu jeodezisinin kullanımı ile jeoid belirlemenin önemini daha da artırmıştır. Uydu jeodezisi yöntemleri ile belirlenen elipsoidal yükseklik (h) ve jeoidden itibaren çekül doğrultusu boyunca ölçülen ortometrik yükseklik $(\mathrm{H})$ arasındaki bağın jeoid ondülasyonu (N) ile kurulmasıyla bölgesel jeoid belirleme çalışmaları hız kazanmıştır. (Aksoy ve ark., 1999). Jeoid belirlenmesi için kaynak olarak kullanılacak veri grubuna göre birçok farklı yöntem kullanılmıştır. Bu yöntemlerin bir kısmı noktaların gravite değerleri ile çözüm yaparken büyük bir kısmı da noktaların elipsoidal ve ortometrik yükseklik değerlerini kullanarak jeoid ondülasyonunu modellemektedir. Geoistatiksel enterpolasyon yöntemlerden biri olan Kriging yöntemi ve Kollokasyon yöntemi de bu yöntemlerden ikisidir. Kriging yöntemi, Güney Afrikalı D.G.Krige’nin adına atfen uyarlanmış tarafsız hataların karesini en küçüklemeye yönelik bir tahmin yöntemi olup geostatistiksel modellemenin son aşamasıdır. Kriging teorisi rastgele alan teorisi ile ilişkili olup, rastgele alanların optimum tahmini olarak da tanımlanmaktadır. En Küçük Kareler Kollokasyon (EKKK) yöntemi; matematiksel modeli bir kısmı olan fonksiyonel modelin sinyal adı verilen sapmaları içermesi durumda, en uygun kestirim değerlerinin en küçük kareler yöntemine göre belirlendiği bir enterpolasyon yöntemidir (Demirel, 1977). Bu yöntemin birçok kullanım alanı olduğu gibi jeodezik çalışmalarda da sıklıkla kullanılmıştır (Doğanalp, 2016; Doğanalp ve Selvi, 2015; Jarmolovski, 2013).

Bu çalışmanın amacı, ortometrik yükseklik ile elipsoidal yükseklik arasındaki ilişkiyi iki farklı yaklaşım modeli kullanarak belirlemektir. Bu amaç için Samsun bölgesinde bir uygulama yapılmıştır. Uygulama sonuçları karşılaştırılarak yöntemlerin uygunluğu irdelenmiştir.

\section{Jeoid Belirleme Yöntemleri}

Pratikte kullanılan nokta yükseklikleri, başlangıç yüzeyi olarak kabul edilen jeoid yüzeyinden olan çekül (düşey) doğrultusu boyunca uzaklıktır. Bu tanımlamaya göre, yeryüzündeki herhangi bir noktadan başlangıç olarak kabul edilen sıfır yükseltili jeoid çekül doğrultusunda inilen dikin boyu o noktanın ortometrik yüksekliği olarak anlaşılmaktadır (Bolat, 2013). Pratikte kullanılan ortometrik yüksekliklerin başlangıç yüzeyi olan jeoidi ise matematiksel olarak ifade etmek oldukça güçtür. Bu durumda pratikte kullanılmayan geometrik yüksekliklerden fiziksel yüksekliklere geçişin 
sağlanabilmesi gerekmektedir. Bu da ancak ortometrik yüksekliklerin başlangıç yüzeyi olan jeoid yüzeyinin üç boyutlu kartezyen sistemlerle ilişkilendirilebilen ve parametreleri belli olan bir referans elipsoidinden olan elipsoidal yüksekliklerinin bilinmesiyle mümkündür (Soycan, 2002). Elipsoidal yükseklikler geometrik yükseklikler olup, pratik ölçme, mühendislik ve jeofizik uygulamalarında fiziksel bir anlamı yoktur (Featherstone, 1998).

Geometrik yüksekliklerden fiziksel yükseklere geçişte işlem adımlarının kısalması ve pratikte uygulamaların hız kazanması jeoid yüzeyinin modellenmesi ile mümkün olabilir. Bölgelerde jeoid ondülasyonları bilinen noktalardan hareketle oluşturulacak bir jeoid yüzey modelinin matematiksel ifadesi, ara noktaların jeoid ondülasyonlarının elde edilmesinde oldukça kolaylık sağlayacaktır. Nokta yüksekliklerinin ölçülmesi iki farklı yüzeye göre yapılır. Yapılan jeodezik ölçmelerde, noktanın jeodezik koordinatlarının hesabı, ölçme bölgesindeki yeryuvarının şekline ve büyüklüğüne büyük ölçüde yakınsayan bir elipsoit üzerinde yapılır. Ölçme aletleri ile fiziksel yeryüzü üzerinde yapılan ölçmeler ise jeoid ile ilgilidir. Bu iki yüzey çakışmaz ve iki yüzey arasındaki farka jeoid ondülasyonu veya jeoid yüksekliği denir ve N ile gösterilir (Şekil 1) (Grafarend, 1994).

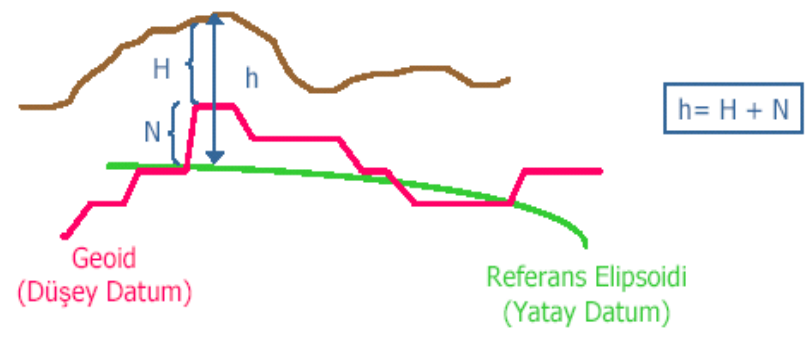

Şekil 1. Jeoid ondülasyonu (URL1)

Jeoid belirleme yatay konumu bilinen bir noktada, jeoid yüksekliğinin sayısal veya analog olarak elde edilmesini sağlayacak biçimde verilerin modellenmesidir (Yılmaz, 2005). GPS tekniğinin jeodezik amaçlar için kullanılmasında elipsoidal yükseklikler (h) sistemin referans elipsoidine dayalı olarak elde edilirler. Ancak çoğu mühendislik çalışmalarında elipsoidal yükseklikler yerine, jeoide göre tanımlanan ortometrik yüksekliklere $(\mathrm{H})$ gereksinim duyulur. Bu nedenle, GPS tekniği ile elde edilen elipsoidal yüksekliklerin ortometrik yüksekliklere en uygun biçimde dönüştürülmesi, uygulamalarda üstesinden gelinmesi gereken bir problemdir (Erol ve Çelik, 2005).

Jeoid belirleme yöntemleri, eldeki mevcut verilere ve kullanılan modellere göre sinıflandırılabilir (Sjöberg,1994; Bolat 2013).

- Astrojeodezik yöntemle jeoid belirleme

- $\quad$ Gravite değerlerine göre jeoid belirleme

- Sayısal yoğunluk modeline göre jeoid belirleme

- Jeopotansiyel model yaklaşımı ile jeoid belirleme 
- Kombine yöntemle jeoid belirleme (remove-restore)

- GPS/Nivelman Yöntemine göre jeoid belirleme (Jeoid Yüzey Modelleri)

- Geoistatiksel enterpolasyon yöntem

- Kollokasyonla modelleme ile jeoid belirleme

- Sonlu elemanlar yardımı ile jeoid belirleme

- Yapay Sinir Ağı tekniği ile jeoid belirleme

- $\quad$ Bulanık mantık ile jeoid belirleme

\subsection{En Küçük Kareler Kollokasyonu İle Jeoid Belirleme}

Jeodezik amaçlı fonksiyonel modellerin çözümüne ilişsin olarak; En Küçük Kareler yöntemine göre dengeleme, filtreleme (süzgeçleme) ve prediksiyon (enterpolasyon ya da ekstrapolasyon) aşamalarının birlikte uygulanarak yapıldığı işleme kollokasyon adı verilir (Öztürk 1992). Kollokasyonda uygulanan dengeleme modelinin, genel dengeleme modellerinden farkı ölçme ve hatasının yanı sıra fonksiyonel modelin sinyal adı verilen bir hata içermesidir. Jeoid yüksekliklerinin elde edilmesine ilişkin genel fonksiyonel eşitlik,

$$
\ell+V=A x+s
$$

şeklindedir. Burada, $\ell$ ölçüleri, $V$ rasgele ölçü hatasını, $A x$ trend yada deterministik kısım, s ise sinyali (fonksiyonel modelin hatası) göstermektedir.s'nin istatistiksel durumu korelasyon fonksiyonlarından elde edilen kofaktör matrisi ile belirlenir (Kutoglu et al. 2006). EKKK yöntemi filtreleme (trend belirleme), deneysel kovaryansin hesabı ve tahmin noktalarında sinyalin kestirimi gibi üç aşama ile uygulanır.

Filtreleme (Trend Belirleme): EKKK yönteminde verilere uygun modelin belirlenmesi gerekmektedir. $\mathrm{Bu}$ ise fonksiyonda trend geçirme işlemi olarak adalandırılır. Trend, ele alınan fonksiyonel modele uygun yüzey olarak adlandırılır. Dengeleme modeli, ele alınan bu trend yüzeyinden olan sapmalar ile birlikte uygulanır. Jeoid belirlemede jeoid ondülasyonuna uygun olan fonksiyonun belirlenmesi gerekmektedir. Bu fonksiyon lineer, polinomal, spline, trigonometrik olabilir. (Demirel, 1977; Doğanalp ve Selvi, 2015; Doğanalp, 2016). Bu çalışmada polinomsal enterpolasyon trend olarak seçilmştir. Kollokasyonda; eğer bir trend yüzeyi ilişskisi söz konusu olmaz ise, bu durumda fonksiyon yerine sabit bir terim ya da sayı gelir.

Deneysel Kovaryansın Hesabı: EKKK yönteminin en büyük farklılı̆̆ı sinyal değerleri için oluşturulan deneysel kovaryanslardır. Sinyallerin istatistiksel davranışları uygun bir kovaryans fonksiyonu ile elde edilen kofaktor matrisi $\left(C_{q}\right)$ ile belirlenir. Kovaryans matrisi elemanları tahmin 
edilen ve ölçülen noktalar arasındaki uzaklık $(q)$ kullanılarak elde edilir. Verilerin durumuna göre birçok kovaryans fonksiyonu (Gauss, Hirvonen, Lauer, Markov's, üstel v.b.) tanımlanmıştır (Tscherning ve Rapp, 1974; Moritz, 1976; Musyoka, 1999; Krynski ve Lyszkowicz, 2006). Bu çalışmada Hirvonen fonksiyonu kullanılmıştır.

Tahmin Noktalarında Sinyalin Kestirimi: EKKK'unda tahmin değeri sinyallerdir. Bu değerlerin tahmininde bilinen nokta sinyalleri ve aralarındaki korelasyon kullanılır. Ölçüler, referans (s) ve tahmin ölçüleri $\left(\mathrm{s}_{\mathrm{p}}\right)$ olarak ikiye ayrılır. Referans noktaları ve tahmin noktaları için ve iki nokta grubu arasındaki kovaryans matrisleri elde edilir.

$$
\begin{aligned}
& \mathrm{C}_{s s}=\left[\begin{array}{ccccc}
C_{s}(0) & C_{s 1 s 2} & C_{s 1 s 3} & \ldots . . & C_{s 1 s n} \\
C_{s 2 s 1} & C_{s}(0) & C_{s 2 s 3} & \ldots . . & C_{s 2 s n} \\
C_{s 3 s 1} & C_{s 3 s 2} & C_{s}(0) & \ldots . . & C_{s 3 s n} \\
\ldots . & \ldots . . & \ldots . . & \ldots . . & \ldots . . \\
C_{s n s 1} & C_{s n s 2} & C_{s n s 3} & \ldots . . & C_{s}(0)
\end{array}\right], C_{s p s p}=\left[\begin{array}{ccccc}
C_{s}(0) & C_{s 1 s 2} & C_{s 1 s 3} & \ldots . . & C_{s 1 s m} \\
C_{s 2 s 1} & C_{s}(0) & C_{s 2 s 3} & \ldots . . & C_{s 2 s m} \\
C_{s 3 s 1} & C_{s 3 s 2} & C_{s}(0) & \ldots . . & C_{s 3 s m} \\
\ldots . . & \ldots . & \ldots . . & \ldots . . & \ldots . . \\
C_{s m s 1} & C_{s m s 2} & C_{s m s 3} & \ldots . . & C_{s}(0)
\end{array}\right], \\
& \mathrm{C}_{\mathrm{sps}}=\left[\begin{array}{ccccc}
C_{s}(0) & C_{s 1 s 2} & C_{s 1 s 3} & \ldots . . & C_{s 1 s n} \\
C_{s 2 s 1} & C_{s}(0) & C_{s 2 s 3} & \ldots . . & C_{s 2 s n} \\
C_{s 3 s 1} & C_{s 3 s 2} & C_{s}(0) & \ldots . . & C_{s 3 s n} \\
\ldots . & \ldots . . & \ldots . . & \ldots . & \ldots \ldots . \\
C_{s m s 1} & C_{s m s 2} & C_{s m s 3} & \ldots . . & C_{s}(0)
\end{array}\right]
\end{aligned}
$$

Buradan, $Q=\frac{C}{m_{0}^{2}}$ eşitliği ile kovaryans matrisleri elde edilir. Ölçülerin kovaryans matrisi $Q_{\ell \ell}$ ve sinyallerin kovaryans matrisi $Q_{s s}$ kullanılarak toplam kovaryans matrisi $\bar{Q}$ elde edilir. Elde edilen bu modelden $s$ sinyallerinin ve $V$ düzeltmeleri için çözüm

$$
x=\left(A^{T} Q^{-1} A\right)^{-1} A^{T} Q^{-1} \ell ; s=Q_{s s} Q^{-1}(\ell-A x) ; V=Q_{\ell \ell} \bar{Q}^{-1}(\ell-A x)
$$

eşitliklerle yapılır (Doğanalp, 2016)..Tahmin noktalarındaki sinyal $\left(s_{p}\right)$ ve jeoid ondülasyonu değerleri $(N p)$ ise;

$$
s_{p}=Q_{s p s} Q^{-1}(\ell-A x) ; N_{p}=A_{p} x+s_{p}
$$

eşitlikleri ile bulunur. Uygulanan modelin doğruluk kriteri olarak karesel ortlama hata $m_{0}$ hesaplanır.

$$
m_{0}= \pm \sqrt{\frac{\left(N_{p}-\ell\right)^{2}}{m}}
$$

Burada, $m$, tahmin noktalarının saysısını göstermektedir (Doğanalp, 2016). 


\subsection{Kriging Yöntemi ile Enterpolasyon}

Kriging yöntemi, jeoistatistiksel modelleme yönteminin son aşamasıdır. Jeoistatistiksel yöntemle modellemede, verilerin istatistiksel analizi yapıldıktan sonra, yapısal analiz için yarıvariogram modellemesi yapılır. Yarıvariogram, örnek çiftleri arasındaki h uzaklığının bir fonksiyonu olarak incelenen değişkenin uzaysal bağımlılık derecesini ifade eder. Eldeki veriler kulanılarak deneysel yarı-variogram elde edilir. Daha sonra bu deneysel yarı-variogram matematiksel modele uydurulur. Bu matematiksel yarı-variogram ise Kriging hesaplama işleminin girdisini oluşturur. Yarıvariogram aşağıdaki bağıntı ile hesaplanır.

$$
\gamma(h)=\frac{1}{2 N(h)} \sum_{i=1}^{N(h)}\left[Z\left(x_{i}\right)-Z\left(x_{i}-h\right)\right]^{2}
$$

Burada, $\gamma(\mathrm{x})$ yarı-variogram değeri, $\mathrm{h}$, i ve diğer noktalar arasındaki mesafe, $\mathrm{N}(\mathrm{h}): \mathrm{h}$ uzunluğundaki nokta çiftleri sayısı (ya da bölge içindeki h vektörü sayısı), Z( $\left.\mathrm{x}_{\mathrm{i}}\right)$ : değişkenin i noktasındaki ölçülen değeri, $\mathrm{Z}\left(\mathrm{x}_{\mathrm{i}}-\mathrm{h}\right)$ : değişkenin $\left(\mathrm{x}_{\mathrm{i}}-\mathrm{h}\right)$ noktasında ölçülen değeridir. $\mathrm{Bu}$ deneysel yar1-variogram fonksiyonu her doğrultuda ve her ölçüm çifti için hesaplanır daha sonra uygun bir parametrik fonksiyon uydurulur. Literatürde en çok kullanılan modeller, küresel, üstel (exponential), gauss, ve doğrusal modellerdir. Bu modellerde $a$ etki mesafesi (range), yani konumsal bağlılı̆̆ın mesafesidir. c eşik değer (sill), yani maksimum varyansdır, co kontrolsüz etki varyansı (nugget effect), yani çalışma alanının homojenliğini ifade eden kısım ve h uygulama mesafesidir. Deneysel yarıvariograma uydurulan matematiksel model Kriging interpolasyonu için gerekli olan giriş parametrelerini (ağırlık katsayılarını) sağlar. Kriging yönteminin temel bağıntısı aşağıda verildiği gibidir.

$$
Z\left(x_{0}\right)=\sum_{i=1}^{N} W_{i} Z\left(x_{i}\right)
$$

Burada; $\mathrm{Z}\left(\mathrm{x}_{0}\right)$, $\mathrm{x}_{0}$ noktasında bilinmeyen ancak tahmin edilen $\mathrm{Z}$ değeri, $W_{i}, Z\left(x_{0}\right)$ 'nin hesabında kullanılan her bir $Z\left(x_{i}\right)$ ye karşılık gelen ağırlık değerleri, $\mathrm{Z}_{\left(\mathrm{X}_{\mathrm{i}}\right)} \mathrm{Z}_{(\mathrm{X} 0)}$ 'nin tahmin edilmesinde kullanılan bilinen verileri, $\mathrm{N}$ ise $Z\left(x_{0}\right)$ 'in hesabında kullanılan nokta sayısıdır. Simple kKriging, Ordinary Kriging, Universal Kriging, Cokriging, Indicator Kriging gibi birçok Kriging yöntemi vardır. Bu çalışmada en yaygın iki yöntem olan Simple Kriging ve Ordinary Kriging kullanılmıştır. Simple Kriging verilerin normal dağılıma uymasını gerektirir. Verilerin durumuna bağlı olarak farklı Kriging yöntemleri kullanılmaktadır. 


\section{Sayısal Uygulama}

Çalışma alanı olarak, Samsun ili kent bilgi sistemi oluşturma çalışmaları projesinin verileri kullanılmıştır. Yapılan çalışmada yaklaşık 421 noktanın yatay koordinatları, elipsoidal ve ortometrik yükseklik değerleri $(X, Y, h, H)$ elde edilmiştir. Bu noktalardan nokta yoğunluğu ve uzaklık değerlerine göre seçilen 40 tanesi uygulama verisi olarak alınmıştır.

EKKK Yöntemi Uygulaması: EKKK yöntemi uygulamasında uygulama verilerinden 20 nokta referans noktası, diğer noktalar tahmin noktası olarak alınmıştır. Verilerden elde edilecek fonksiyon olarak polinomsal fonksiyon seçilmiştir. MatLab uygulama dilinde yazılmış olan programla veriler 1., 2. ve 3. derece polinomsal yönteme göre kollokasyon yöntemi ile çözülmüş ve (4) eşitliğiyle karesel ortalama hatalar elde edilmiştir. Veri grubu elde edilirken deneysel varyans Hirvonen fonksiyonu kullanılarak elde edilmiştir. Yapılan çalışmanın İş akışı Şekil 2'de verilmiştir.

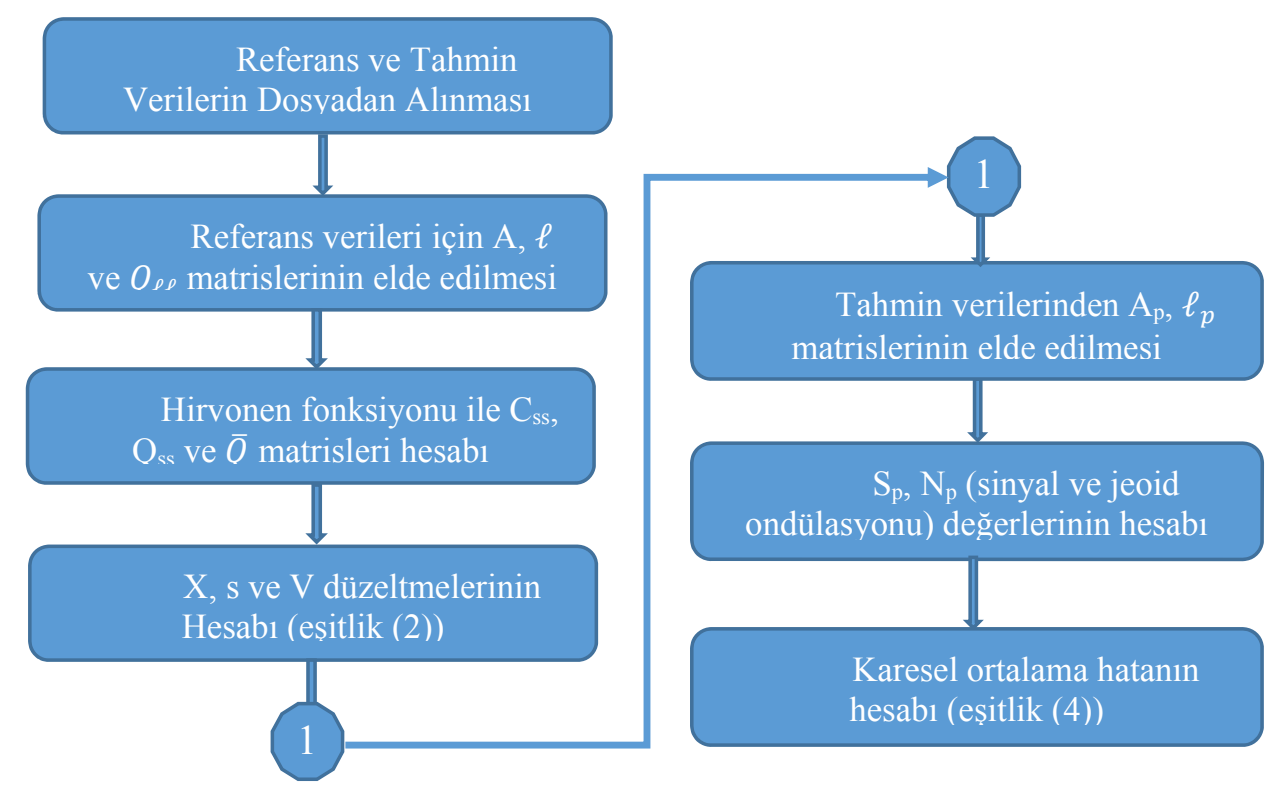

Şekil 2. EKKK Yöntemi İş Akışı

Kriging Yöntemi Uygulaması: Kriging yöntemi için ArcMap 10.3 programı kullanılmıştır. Öncelikle verilerin istatistiksel analizi yapılmış olup, elde edilen sonuçlar Şekil 3'de, verilerin QQPlot grafiği Şekil 4'de verilmiştir. QQ (Quantile-Quantile) plot, eğer veriler $45^{0}$ 'lik doğru üzerinde yoğunlaşmışsa, bu verilerin normal dağılıma uyduğunu göstermektedir. Şekil 3 ve 4 incelendiğinde verilerin normal dağılım olduğu görsel olarak dahi görülmektedir. Bu durum Simple Kriging uygulamasının yeterli olacağını göstermektedir. 


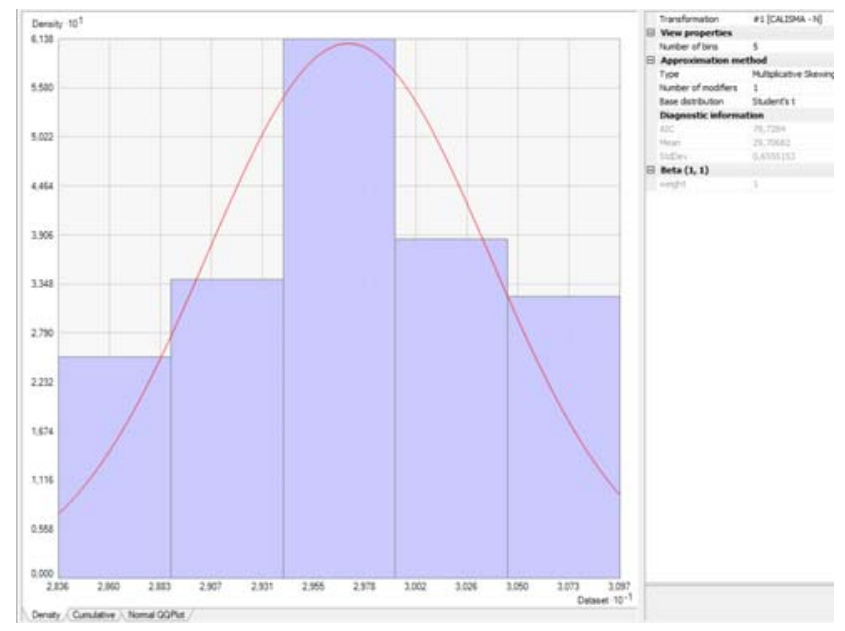

Şekil 3. Verilerin İstatistiksel analizi ve histogramı

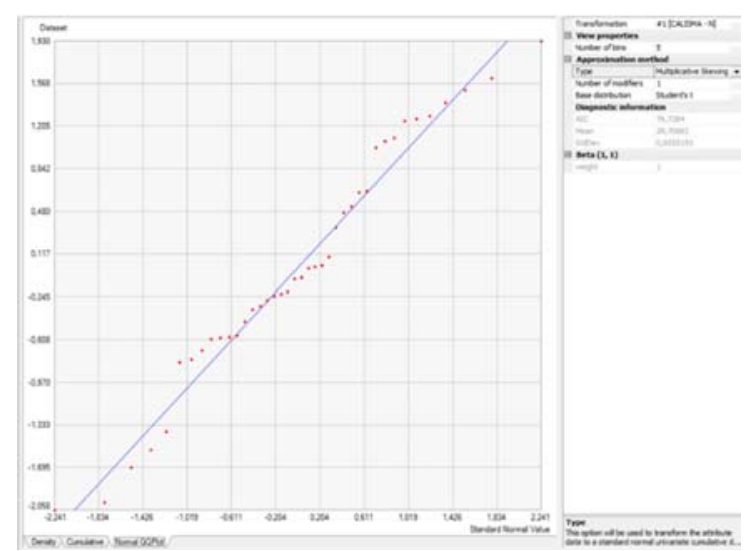

Şekil 4. Verilerin Normal QQ-Plot Gösterimi

Verilerin normal dağılıma uyduğu teyit edildikten sonra, verilerin yarı-variogram analizi yapılmıştır. Yapılan denemeler sonucunda aşă̆ıdaki parametreler kullanılarak uygun yarıvariogramlar elde edilmiştir (Tablo 1).

Tablo 1. Simple Kriging Yöntemi İçin Kullanılan Parametreler

\begin{tabular}{ll}
\hline Aralık (Lag) & $1500 \mathrm{~m}$ \\
Maksimum Mesafe & $30000 \mathrm{~m}$ \\
Tolerans Açısı & $20^{\circ}$ \\
Tolerans Açısı Mesafesi & $2 \times 1$ lag \\
\hline
\end{tabular}

Elde edilen yarı-variogram grafikleri Şekil 5 ve 6'de, yar1-variogram parametreleri ise Tablo 2'de verilmiştir. 


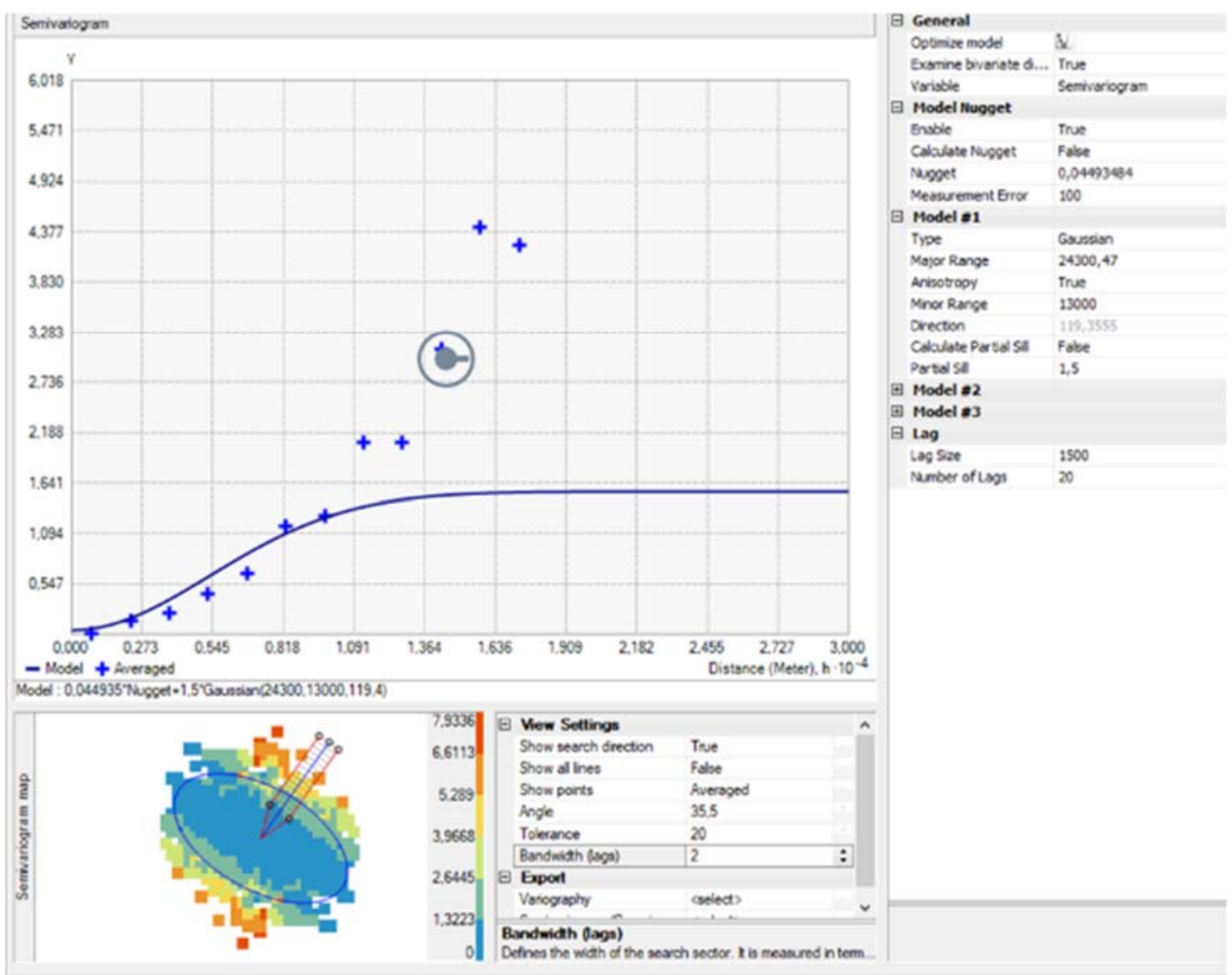

Şekil 5. Yar1-Variogram $35,5^{0}$ Yönünde

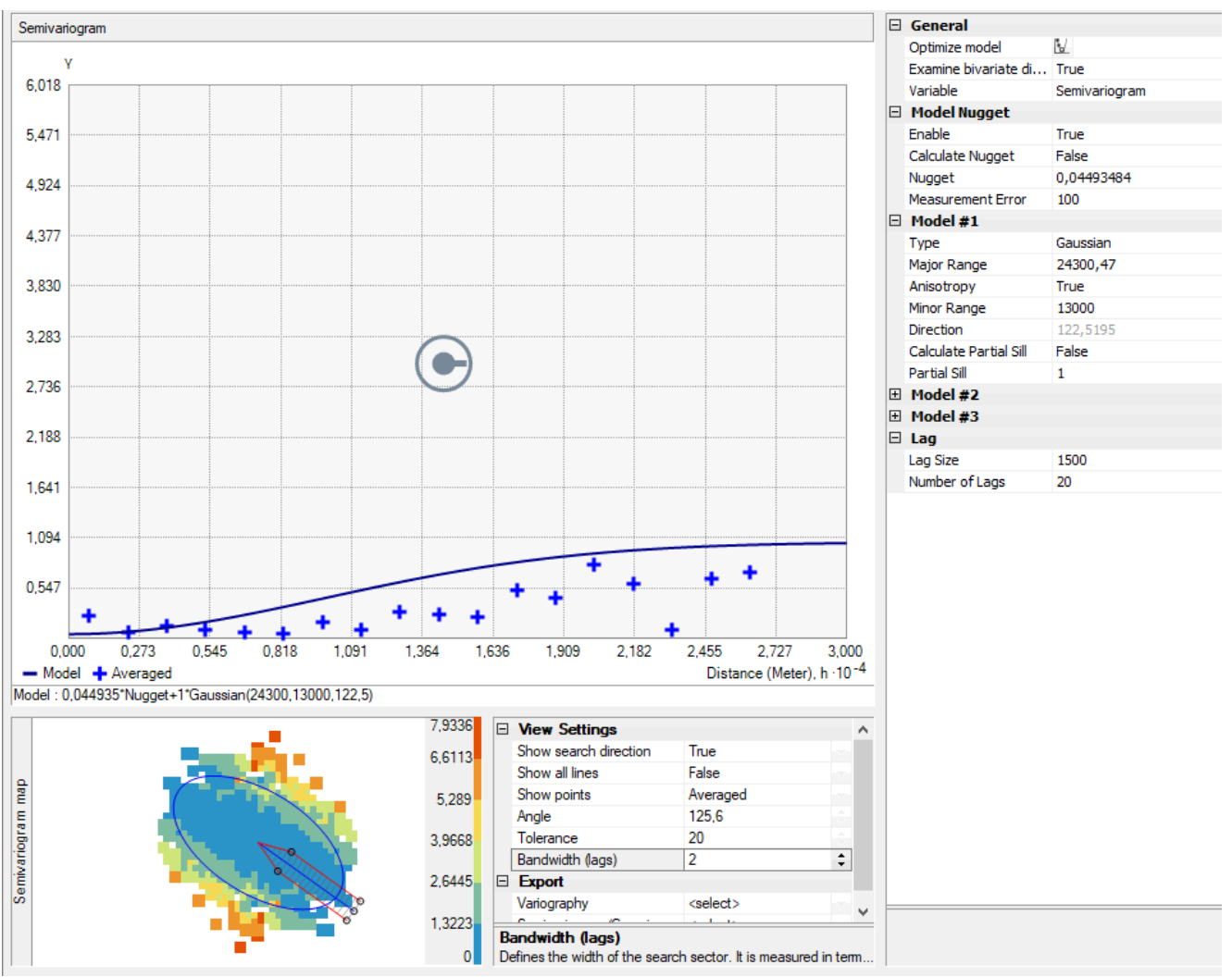

Şekil 6. Yar1-Variogram $125^{0}$ Yönünde 
Tablo 2: Yar1-Variogram Parametreleri

\begin{tabular}{ll}
\hline Model & Gaussian \\
Ana Etki Mesafesi & 24000 \\
İkincil Etki Mesafesi & 13000 \\
Yön & $120^{\circ}$ \\
Külçe Etkisi & 0,05 \\
Kismi Sill & 1,5 \\
\hline
\end{tabular}

Matematiksel yarı-variogram modeli elde edildikten sonra Simple Kriging modülü ile N değerleri tahmin edilmiştir. Şekil 7 ve 8 'de verilen çapraz doğrulama sonuçları, elde edilen tahminlerin kabul edilebilirliğini göstermektedir.

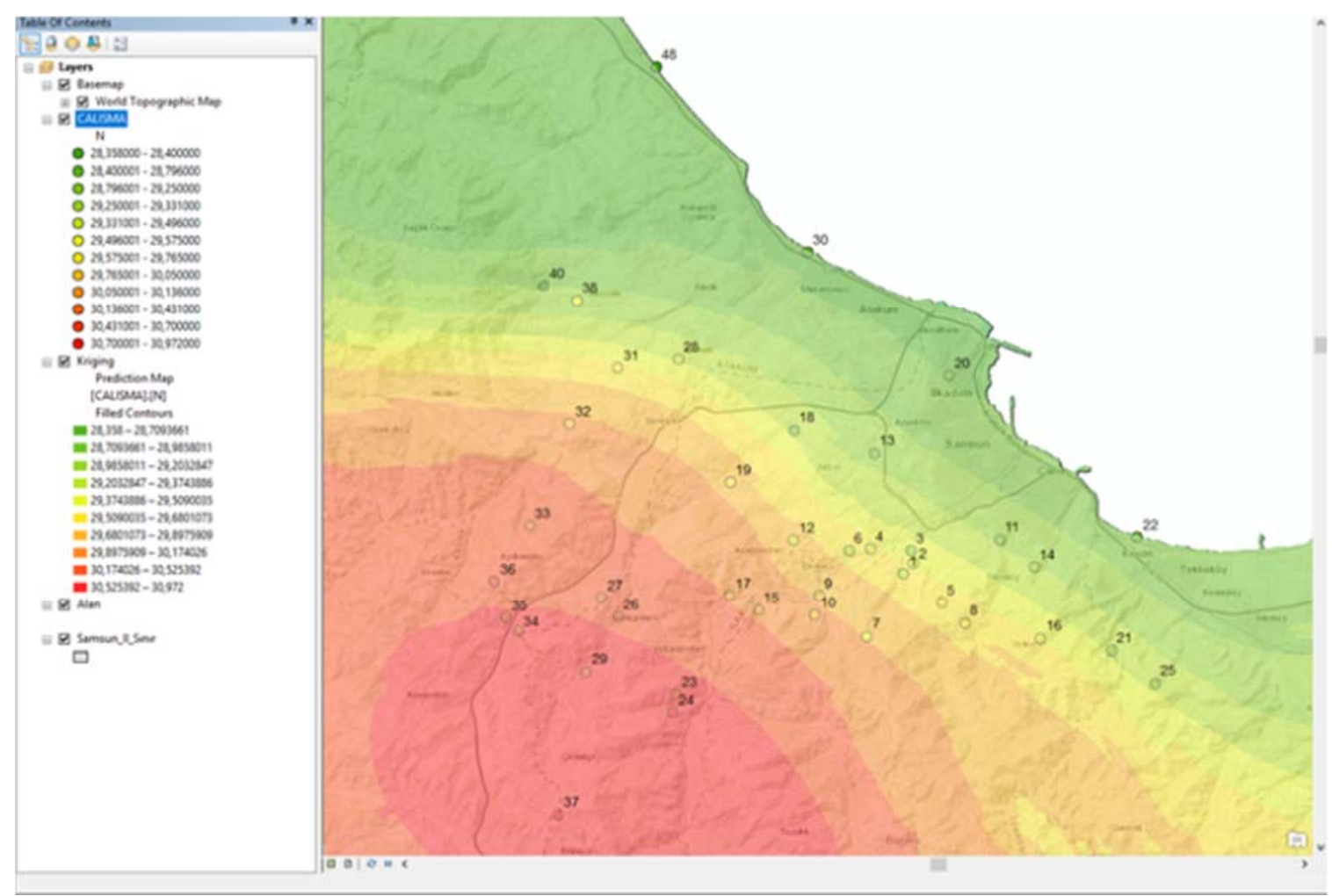

Şekil 7. Çalışma sahasının simple kriging ile modellenmesi 


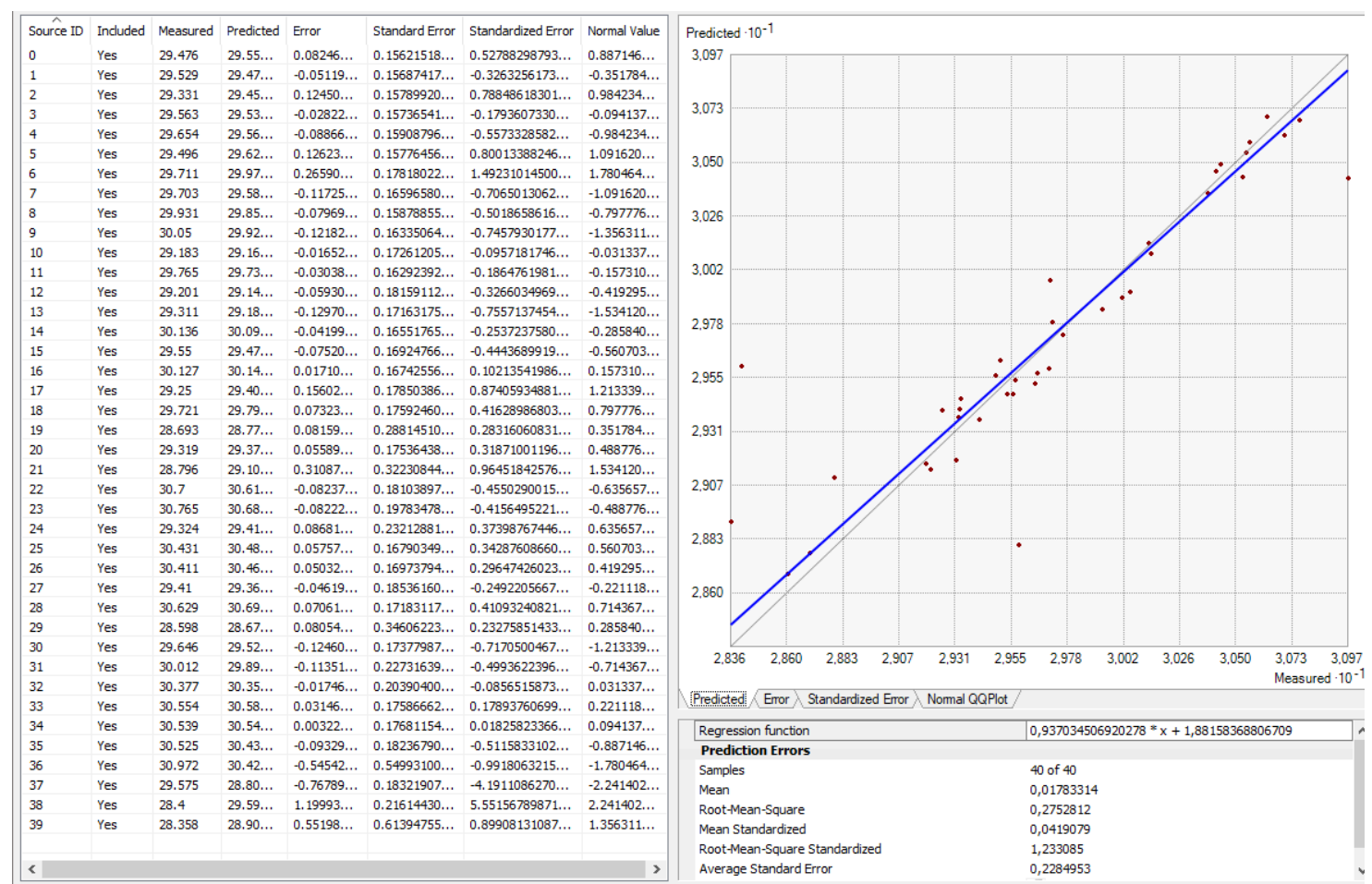

Şekil 8. Hesaplama Hataları ve Hataların grafiksel gösterimi

Şekil 7'de çalışma sahasının modellenmiş hali ve modellemede kullanılan veriler renk kodu ile gösterilmiştir. Burada sadece 40 nolu veri ile 38 nolu verinin olduğu bölgede uyumsuzluk vardır. Diğer bölgeler oldukça uyumludur. Şekil 8'de ise verilerin hesaplanmasındaki hata payları ve hataların grafiksel gösterimi verilmiştir. Şekil incelendiğinde en büyük tahmin hatasının 38 nolu noktada olduğu görülmektedir.

\section{Sonuçlar ve Öneriler}

Yapılan uygulama sonucunda EKKK yöntemi ile ilgili 1., 2., ve 3. derece polinomlarla yapılan çözümlerden aşağıdaki karesel ortalama hata değerleri elde edilmiştir.

Tablo 3. EKKK Yöntemi Sonuçları

\begin{tabular}{|c|c|c|}
\hline $\begin{array}{l}\text { Polinomun } \\
\text { Derecesi }\end{array}$ & $\begin{array}{l}\text { Karesel Ortalama } \\
\text { Hata }(\mathrm{cm})\end{array}$ & Polinom Eşitliği \\
\hline 1 & 24,30 & $N=29.597+-1,095 * 10^{-4} * X+-6,724 * 10^{-5} * Y$ \\
\hline 2 & 24,43 & 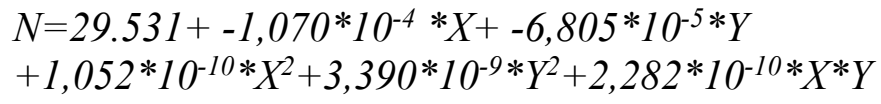 \\
\hline 3 & 36,21 & 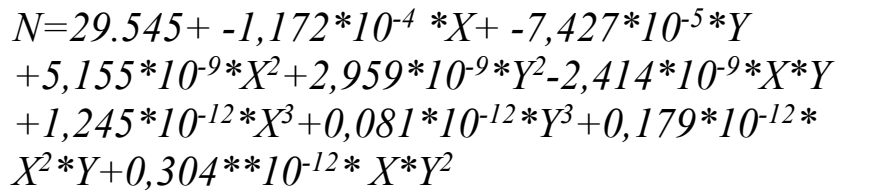 \\
\hline
\end{tabular}


Elde edilen karesel ortalama hata değerleri irdelendiğinde 1. ve 2. derece polinomlardan elde edilen değerlerin oldukça birbirine yakın olduğu ve kabul edilebilir olduğu görülmüştür. 3. derece polinomdan elde edilen karesel ortalama hata değeri büyüme eğilimi göstermiştir. Ayrıca 4. derece polinom çözümü de denenmiş fakat karesel ortalama hatanın büyümesi nedeniyle sonuçlardan çıkarılmıştır. Bu durumda EKKK yöntemi ile jeoid belirlemede bu uygulama bölgesi için 1. derece polinomun yeterli olduğu söylenebilir.

Kriging yöntemi ile elde edilen verilerden aşağıdaki sonuçlar elde edilmiştir.

Tablo 4. Simple Kriging Yöntemi ile elde edilen sonuçlar

\begin{tabular}{lc}
\hline Karesel ortalama hata & $27,5 \mathrm{~cm}$ \\
Ortalama standart hata & $22,8 \mathrm{~cm}$ \\
Polinom Eşitliği & $\mathrm{N}=0,937 * \mathrm{X}+1,88$ \\
\hline
\end{tabular}

EKKK ve Kriging yöntemlerinin sonuçları değerlendirildiğinde her iki yöntemin de yaklaşık aynı karesel ortalama hatayı verdiği $(24,30 \mathrm{~cm}$. ve 27,5 cm.) ve bu değerlerin jeoid belirleme işlemi için kabul edilebilir olduğu görülmüştür.

\section{Kaynaklar}

Aksoy, A. ve Güneş İ.H.(1990). Jeodezi I Ders Notları. İTÜ. Matbaası, Gümüşsuyu, İstanbul.

Aksoy, A., Ayhan T., Çelik R.N., Demirel H., Deniz R. ve Gürkan O. (1999). Güncel gelişmeler ışı̆̆ında mekansal bilgi sistemleri için jeodezik altyapı ve problemleri. TMMOB Harita ve Kadastro Mühendisleri Odası İstanbul Şubesi Eğitim dizisi, 28 Mayıs, İstanbul.

Jarmolovski, W. (2013), A priori noise and regularization in least squares collocation of gravity anomalies. Geodesy and cartography. Vol. 62, No 2, pp. 199-216

Featherstone, W.E., Dentith,M.C., Kirbiy,J.F., (1998). Strategies for accurate determination of orthometric heights from GPS. Survey Review. 34(267), pp. 278-296

Soycan, M. (2002). Jeoit yüksekliklerinin GPS ve hassas trigonometrik nivelman ölçüleri ile belirlenmesi. Doktora Tezi, Yıldız Teknik Üniversitesi, Fen Bilimleri Enstitüsü. İstanbul.

Grafarend, E.W. (1994). What is geoid? Geoid and itr geophysical interpretations Eds. Petr Vanicek and Nikolas T. Chrisou. Chapter 1. CRC press, Boca Raton, FL, USA.

Yılmaz, M., (2005). İstanbul Metropolitan Alanda Geoit Araştırması. Doktora Tezi, İstanbul Teknik Üniversitesi, Fen Bilimleri Enstitüsü, İstanbul.

Erol, B. ve Çelik, R.N. (2005). Prezisyonlu lokal geoit modeli belirlenmesinde örnek bir inceleme GPS/Nivelman ve geoit yüksekliklerinin entegrasyonu. TMMOB Harita ve Kadastro Mühendisleri Odası, 10. Türkiye Harita Bilimsel ve Teknik Kurultayl. Ankara. 28 Mart- 1 Nisan.

Bolat S. (2013), Lokal jeoid belirlemede kullanılan enterpolasyon yöntemleri: Samsun ili örneği. Yüksek Lisans Tezi, Ondokuz Mayıs Üniversitesi, Fen Bilimleri Enstitüsü. Samsun.

Sjöberg, L.E. (1994). Techniques for jeoid determination, Geoit and its geophysical interpretations, Eds. Petr Vanicek and Nikolas T. Christou. Chapter 2, CRC pres, Boca Raton, FL, USA.

Öztürk, E., Şerbetçi, M. (1992). Dengeleme Hesabı III. Karadeniz Teknik Üniversitesi yayınları. Trabzon.

Doganalp, S. and Selvi, H.Z., (2015), Local geoid determination in strip area projects by using polynomials, least-squares collocation and radial basis functions. J. Measurement. 73, No. 9, 429-438.

Demirel, H. (1977). En Küçük Kareler Yöntemine göre prediksiyon ve Kollokasyon. İDMMA. İstanbul.

Doğanalp, S., (2016). Geoid height computation in strip-area projects by using least squares collocation, Acta Geodyn. Geomater. Vol. 13, No. 2 (182), 167-176. 
Krynski, J. and Lyszkowicz, A. (2006). Centimetre quasigeoid modeling in Poland using heterogeneous data. Proceedings of the 1st International Symposium of the International Gravity Field Service, "Gravity Field of the Earth" Harita Dergisi. Special Issue 18, pp. 37-42, Ankara, Turkey.

Moritz, H. (1976). Covariance function in least squares collocation. Reports of the Department of Geodetic Science, No. 240, Ohio State University.

Tscherning, C.C. and Rapp, R.H. (1974). Closed covariance expressions for gravity anomalies, geoid undulations, and deflections of the vertical implied by anomaly degree variance models. Reports of Department of Geodetic Science, No. 208, The Ohio State University, Columbus, Ohio.

URL1: https://jeodezi.boun.edu.tr/sites/jeodezi.boun.edu.tr/files/dosyalar/files/JEODEZI BUKRDAE GED. pdf, (Erişim Tarihi: 05 Ekim 2018). 